\title{
Degradation analysis of thin film photovoltaic modules under outdoor long term exposure in Spanish continental climate conditions
}

\author{
Santiago Silvestre $^{\mathrm{a}, *}$, Sofiane Kichou ${ }^{\mathrm{a}}$, Letizia Guglielminotti ${ }^{\mathrm{a}}$, Gustavo Nofuentes ${ }^{\mathrm{b}, \mathrm{c}}$, Miguel Alonso-Abella ${ }^{\mathrm{d}}$

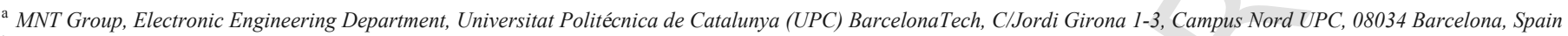 \\ b IDEA Research Group, University of Jaén, Campus de Las Lagunillas, 23071 Jaén, Spain \\ Centre for Advanced Studies in Energy and Environment, University of Jaén, Campus Las Lagunillas, 23071 Jaén, Spain \\ d CIEMAT/DER, Avda. Complutense, 22, 28040 Madrid, Spain
}

\section{A R T I C L E IN F O}

Article history:

Received 11 July 2016

Received in revised form 3 October

2016

Accepted 18 October 2016

Available online $\mathrm{xxx}$

Keywords:

Thin-film

PV modules

Degradation rate (DR)

Performance ratio (PR)

\section{A B S T R A C T}

The present study analyses the degradation of thin film photovoltaic modules corresponding to four technologies: a-Si:H, a-Si:H/ $\mu \mathrm{c}-\mathrm{Si}: \mathrm{H}, \mathrm{CIS}$ and CdTe, under 5 years of outdoor long term exposure in Leganés, Spain. The period of outdoor exposure ranges from January 2011 to December 2015. The degradation rate and the stabilization period are analysed by using two different techniques. Moreover, the evolution of the fill factor and performance ratio is assessed. The CdTe module was found to have the highest degradation rate: $-4.45 \% /$ year, while the CIS module appears to be the most stable with a degradation rate of $-1.04 \%$ /year. The a-Si:H and a-Si:H/ $\mu$ c-Si:H modules present stabilization periods of 24 and 6 months respectively. The CdTe module degrades significantly for a period of 32 months, while the CIS module is the least degraded PV specimen over the whole experimental campaign.

(C) 2016 Published by Elsevier Ltd.

\section{Introduction}

Nowadays thin film photovoltaic (TFPV) modules cover a $10 \%$ of market share with an annual production of $2.4 \mathrm{GWp}$ in 2014 (Institute for Solar Energy Systems, 2016). The most common PV materials used in the mass production of TFPV modules are cadmium telluride (CdTe), copper indium gallium selenide sulphide $\left(\mathrm{Cu}(\mathrm{In}, \mathrm{Ga}) \mathrm{Se}_{2}\right.$, CIGS) and amorphous silicon (a-Si), presenting an annual production in 2014 of $1.9 \mathrm{GWp}, 1.7 \mathrm{GWp}$ and $0.8 \mathrm{GWp}$ respectively (Institute for Solar Energy Systems, 2016).

The main advantages of TFPV modules are their lower production costs and lower temperature coefficients relative to the crystalline (c-Si) and polycrystalline silicon PV modules (Tossa et al., 2016; Virtuani et al., 2010). On the other hand, main problems of TFPV modules are the degradation phenomena after long term outdoor exposure (Jordan and Kurtz, 2013; Meyer and van Dyk, 2003; Mendoza-Pérez et al., 2009; Muñoz-García et al., 2012) and the lower efficiencies in the comparison to c-Si PV modules.

Hydrogenated amorphous silicon (a-Si:H) and hydrogenated amorphous silicon/hydrogenated microcrystalline silicon hetero-junction (a-Si:H/ $\mu \mathrm{c}-\mathrm{Si}: \mathrm{H})$ TFPV modules have conversion efficiencies in the range of $8-13 \%$ and present low production costs and energy pay-back times. However, these TFPV modules are strongly affected by spectral and temperature effects when deployed outdoors (Virtuani and Fanni, 2014; Kichou et al., 2016a,b). The so called Staebler-Wronski effect (SWE) is the cause of light-induced degradation

* Corresponding author.

Email address: Santiago.silvestre@upc.edu (S. Silvestre)
(LID) that strongly affects a $\mathrm{Si}: \mathrm{H}$ and also has effects on (a-Si:H/ $\mu \mathrm{c}-\mathrm{Si}: \mathrm{H}$ ) TFPV modules. It determines the amount of dangling bonds created depending on the operating temperature (Staebler and Wronski, 1977; Van Dyk et al., 2007; Yamawaki et al., 1997).

CdTe TFPV modules are well adapted to the spectrum of solar radiation due to their band gap of $1.45 \mathrm{eV}$. The theoretical efficiency limit for CdTe technology is 29\% (Muñoz-García et al., 2012). However, the average commercial PV module efficiencies are around $10-11 \%$ and the highest efficiency to-date is $17.5 \%$ (Green et al., 2015). Main degradation mechanisms identified in these PV modules are related to $\mathrm{Cu}$ diffusion from the back contact of the cells (Romeo et al., 2000) and to the reduction of the fill factor as a result of shunting effects (Mendoza-Pérez et al., 2009).

$\mathrm{Cu}$ (In, Ga)Se $\mathrm{Se}_{2}$ (CIGS) chalcopyrite semiconductors such as $\mathrm{Cu}(\mathrm{In}) \mathrm{Se}_{2}$ (CIS) are direct-gap polycrystalline semiconductors, having very high optical absorption coefficients (Shah et al., 1999). PV modules based on CIS and CIGS technologies are generally considered to be quite stable and TFPV module efficiencies up to $17.5 \%$ have been recently reported (Institute for Solar Energy Systems, 2016). However, it is estimated that the initial power may decrease by up to $3 \%$ before stabilization (Muñoz-García et al., 2012).

Reliability and lifetime of PV modules are two crucial issues as they are the key for overall system performance and warranty to improve the energy generated. For the case of TFPV modules, the behavior under outdoor exposure is still not fully understood and is currently object of research. A better understanding on this topic would be important for selecting the best PV technology for each specific climatic condition and for improving the reliability and performance of TFPV modules. 
The objective of this work is the analysis of behavior of TFPV modules of four technologies under outdoor long term exposure in a relatively dry and sunny inland site. The period under scrutiny ranges from January 2011 to December 2015.

This paper is organized as follows. Section 2 describes the PV modules used in the study and details the monitoring system. An overview of the degradation analysis methodologies followed in the study is given in Section 3. The results and discussion are presented in Section 4. The conclusions of the study are given in Section 5.

\section{PV modules and experimental setup}

The four PV modules considered in this work correspond to the following thin film technologies: a-Si:H, a-Si:H/ $\mu \mathrm{c}-\mathrm{Si}: \mathrm{H}, \mathrm{CIS}$ and $\mathrm{CdTe}$. The modules were deployed in Leganés, a city $16 \mathrm{~km}$ south east of Madrid (Spain, Latitude: $40^{\circ} 19^{\prime} 42^{\prime \prime} \mathrm{N}$, Longitude: $3^{\circ} 45^{\prime} 55^{\prime \prime} \mathrm{W}$, Altitude: $666 \mathrm{~m}$ ) which lies within the metropolitan area of the latter. Leganés has a Mediterranean climate with strong continental influences and experiences pollution episodes and occasional Saharan dust intrusions as in the case of Madrid. The PV modules were mounted on an equator-facing open rack with a tilt angle of $30^{\circ}$. The tilt angle selected for the open rack was meant to maximize the collection of annual on-plane irradiation. The main parameters of the TMPV modules at standard test conditions (STC): $\mathrm{G}=1000 \mathrm{~W} / \mathrm{m}^{2} \mathrm{AM} 1.5 \mathrm{G}$, $\mathrm{Tc}=25^{\circ} \mathrm{C}$, used in this study are given in Table 1 .

An automatic test and measurement system was used to scan both the electrical and environmental parameters every five minutes over the whole experimental campaign. The experimental setup was intended to scan the current-voltage $(I-V)$ curves of each of the four TFPV modules under study together with some environmental parameters that influence their outdoor performance. A PC-based system controlled by LabVIEW ${ }^{\mathrm{TM}}$ managed the acquisition and storage of data for their subsequent processing. Thus, $I-V$ curves were traced using a PVE PVPM 2540C capacitive load so that 128 current-voltage data points were retrieved from this device in each scan. Additionally, the four PV modules could be tested sequentially using this setup, by means of a switchgear box of solid state relays driven by a multipurpose Agilent 34970A data acquisition/data logger switch unit.

Some external environmental parameters such as the horizontal and on-plane incident irradiance together with its spectral distribution, module temperature, relative humidity, ambient temperature, wind speed and barometric pressure were registered with the above data acquisition/data logger switch unit, so that these parameters were recorded simultaneously with the $I-V$ curve tracing. The in-plane irradiance came from a Kipp \& Zonnen CMP 21 pyranometer with directional response (up to $80^{\circ}$ with $1000 \mathrm{~W} / \mathrm{m}^{2}$ beam) $<10 \mathrm{~W}^{2}$

Table 1

Main parameters of PV modules derived from the PV module manufacturers' data sheet.

\begin{tabular}{|c|c|c|c|c|}
\hline \multirow[t]{3}{*}{ Technology } & \multicolumn{4}{|c|}{ PV module } \\
\hline & $\begin{array}{l}\text { Sharp } \\
\text { NA-121 }\end{array}$ & $\begin{array}{l}\text { Shell Powermax } \\
\text { Ultra } 80 \mathrm{C}\end{array}$ & $\begin{array}{l}\text { First Solar } \\
\text { FS-270 }\end{array}$ & $\begin{array}{l}\text { Kaneka } \\
\text { GEA } 60\end{array}$ \\
\hline & $\begin{array}{l}\mathrm{a}- \\
\mathrm{Si}: \mathrm{H} / \mu \mathrm{c}- \\
\mathrm{Si}: \mathrm{H}\end{array}$ & CIS & $\mathrm{CdTe}$ & a-Si:H \\
\hline Peak power $(\mathrm{W})$ & 121 & 80 & 72.5 & 60 \\
\hline Isc (A) & 3.34 & 2.68 & 1.19 & 1.19 \\
\hline $\operatorname{Voc}(\mathrm{V})$ & 59.2 & 46.6 & 90 & 92 \\
\hline $\begin{array}{l}\text { Temperature coefficient- } \\
\text { power } \delta\left(\% /{ }^{\circ} \mathrm{C}\right)\end{array}$ & -0.24 & -0.43 & -0.25 & -0.23 \\
\hline$\eta(\%)$ & 8.5 & 12.7 & 10 & 6.3 \\
\hline
\end{tabular}

while the spectral irradiance distribution was measured by means of a weatherproof EKO MS-700 grating spectroradiometer whose specifications include a $10-\mathrm{nm}$ spectral resolution. T thermocouples pasted to the rear side of each PV module were used to measure the module temperature, while the relative humidity and ambient temperature were measured by a Young $41382 \mathrm{VC}$ relative humidity/temperature probe with an accuracy at $23{ }^{\circ} \mathrm{C}$ of $\pm 1 \%$ for relative humidity and $\pm 0.3{ }^{\circ} \mathrm{C}$ for temperature. Finally, a Young 05305VM anemometer with an accuracy of $\pm 0.2 \mathrm{~m} / \mathrm{s}$ of wind speed and \pm 3 degrees of wind direction and a Vaisala barometric pressure sensor with an accuracy at $+20{ }^{\circ} \mathrm{C}$ of $\pm 0.10 \mathrm{hPa}$ completed the experimental setup.

Table 3 summarizes a brief statistic of the meteorological parameters recorded for the period of measurements.

\section{Methodology}

The two techniques applied in this study to all modules under test, based on the analysis of the output power of the PV modules, are described in this section. The combination of these two techniques allows a good approach to understand the degradation effects and helps to identify better the degradation rates, stabilization periods and seasonal variations.

\subsection{Effective peak power of the PV modules}

The effective peak power of a PV module, $P^{*}{ }_{M}$, at STC is given by the following equation (Martínez-Moreno et al., 2012; Nofuentes et al., 2006):

$$
P_{M}^{*}=\frac{G^{*} P_{D C}}{G} T F
$$

where $P_{D C}, G$ and $G^{*}$ are the DC output power of the PV module, the irradiance, and irradiance at STC respectively. $T F$ is the thermal factor defined as follows:

$$
T F=\frac{1}{\left[1+\delta\left(T_{m}-T_{m}^{*}\right)\right]}
$$

where $T_{m}$ is the PV module temperature, $T_{m}{ }^{*}$ is the module temperature under $\operatorname{STC}\left(25^{\circ} \mathrm{C}\right)$, and $\delta$ is the power temperature coefficient of the PV modules.

The evaluation of $P^{*}{ }_{M}$ from the monitoring data set was performed after disregarding data recorded at low irradiance values. Specifically, only measurements taken at $G>700 \mathrm{~W} / \mathrm{m}^{2}$ were used.

Table 2

Annual average values of some meteorological parameters along the monitoring cam-

\begin{tabular}{|c|c|c|c|c|}
\hline $\begin{array}{l}\text { Accumulated } \\
\text { horizontal } \\
\text { irradiation }(\mathrm{kW} \mathrm{h} / \\
\left.\mathrm{m}^{2}\right)\end{array}$ & $\begin{array}{l}\text { Average } \\
\text { ambient } \\
\text { temperature } \\
\left({ }^{\circ} \mathrm{C}\right)\end{array}$ & $\begin{array}{l}\text { Minimum } \\
\text { ambient } \\
\text { temperature } \\
\left({ }^{\circ} \mathrm{C}\right)\end{array}$ & $\begin{array}{l}\text { Maximum } \\
\text { ambient } \\
\text { temperature } \\
\left({ }^{\circ} \mathrm{C}\right)\end{array}$ & $\begin{array}{l}\text { Relative } \\
\text { humidity } \\
(\%)\end{array}$ \\
\hline 1774 & 15.0 & 2.7 & 32.1 & 57 \\
\hline
\end{tabular}
paign.

Table 3

Degradation rates of the PV modules.

\begin{tabular}{lllll}
\hline PV module & a-Si:H & CIS & CdTe & Micromorph \\
\hline$D R(\% /$ year $)$ & -2.28 & -1.04 & -4.55 & -2.72 \\
\hline
\end{tabular}


Thus, the shape of varying solar spectra recorded in Leganés above this irradiance threshold closely resembles that of the spectral AM1.5G reference spectrum and consequently no spectral effects are taken into account in Eq. (1). This agreement between recorded spectra and AM $1.5 \mathrm{G}$ reference spectrum is based on the criteria adopted by the International Electrotechnical Commission to state the spectral match of a solar simulator (IEC, 2007), defined by the deviation from the standard spectrum. The experimental assessment of such spectral match is far from being obvious, Thus, the reader is referred to Annex $\mathrm{A}$ at the end of this paper where this empirical evaluation can be found.

The monthly average value of $\mathrm{P}^{*}{ }_{\mathrm{M}}$ was evaluated along the five years of the monitoring campaign.

The degradation rate, $D R$ (\%/year), of the TFPV modules is evaluated by means of a linear least square fitting method of the $P^{*}{ }_{M}$ by using Eq. (3).

$$
D R=100 \frac{12 m}{c}
$$

where $\mathrm{m}$ is the slope of line and $\mathrm{c}$ is the $\mathrm{y}$ intercept of the trend line obtained for $P^{*}{ }_{M}$ (Sharma et al., 2014):

$$
y=m x+c
$$

The analysis of the stabilization period of TFPV modules is based on a second monitoring data filtering process following the procedure used in previous works (Kichou et al., 2016a,b; Hussin et al., 2015). The average monthly value of the monitored $\mathrm{P}_{D C}$ output power of the PV modules was evaluated for restricted ranges of tilted irradiance and working PV module temperature.

\subsection{Power-irradiance technique}

The power-irradiance $(\mathrm{P}-\mathrm{G})$ technique is the second method used in this study to analyze the behavior of the TFPV modules. This method proposed by Hussin et al. (2015) was applied with success to study the degradation of a-Si:H (Kichou et al., 2016a,c) and a-Si:H/ $\mu$ c-Si:HTFPV modules (Kichou et al., 2016b).

A Linear Correlation Approach (LCA) was used to obtain linear regression equations from the actual PV modules DC outputs, $P_{D C}$, as a function of the irradiance, $G$, by means of the following equation:

$$
P_{D C}=A_{G r} \cdot G+C
$$

where $P_{D C}$ is the PV module DC output power, $A_{G r}$ is the gradient, $G$ is the plan-of-array irradiance and $C$ is the ordinate value of $P_{D C}$ at $G=0$.

A data filtering process was carried out in order to avoid problems caused by low values of irradiance $\left(G<700 \mathrm{~W} / \mathrm{m}^{2}\right)$ as in the evaluation of the $D R$ presented in previous section. Eq. (5) is only valid for values of $\mathrm{G}>700 \mathrm{~W} / \mathrm{m}^{2}$.

Finally, the monthly gradient values, $A_{G r}$, of each empirical equation can be plotted to determine the stabilization period (Hussin et al., 2015).

\subsection{Fill factor and performance ratio}

The performance ratio, $P R(\%)$, is used as an indicator of outdoor modules performance and is given by Ishii et al. (2014):

$$
P R=\frac{P_{m}}{P_{m S T C}} / \frac{G}{G^{*}}
$$

where $P_{m}$ is the measured maximum output power of the PV module and $P_{m S T C}$ is the nominal output power of the PV module.

On the other hand, the Fill Factor, FF (\%), is given by the following equation:

$$
F F=\frac{P_{m}}{V o c I s c}
$$

where Isc and Voc are the short-circuit current and open circuit voltage of the PV modules respectively.

The evolution of the monthly values of PR and FF was analysed in all modules under test along the monitoring campaign.

\section{Results and discussion}

\subsection{Evolution of the effective peak power of the PV array}

The evolution of the effective peak power of the four PV modules calculated by using Eq. (1) and monitored data is plotted in Fig. 1. As it can be seen, the decrease rate of the effective peak power, $P^{*}{ }_{M}$, along the monitoring campaign strongly depends on the PV module technology.

Regarding the a-Si:H and micromorph PV modules, an important initial decrease of $P^{*}{ }_{M}$ can be observed during the first months of exposure under outdoor conditions due to the LID phenomenon. After a period of time, the decrease is less significant and $P^{*}{ }_{M}$ fluctuates around a constant value following climatic seasonal changes. A decrease of $P^{*}{ }_{M}$ is observed during the winter months while an increase is observed over the summer months. This seasonal variation in the output power of the a-Si:H and micromorph PV modules is mainly attributed to the effect of temperature on the amorphous material, and has been described previously in several studies (Mendoza-Pérez et al., 2009; Shah et al., 1999; Martínez-Moreno et al., 2012; Sharma et al., 2014; Hussin et al., 2015; Cañete et al., 2014). Thus, the regeneration in summer months can be assigned to the light-induced annealing (Meyer and van Dyk, 2003), spectral effect (Carlson, 2003) and thermal regeneration (Yamawaki et al., 1997; Rüther et al., 2008).

The evolution of $P^{*}{ }_{M}$ of the CdTe PV module presents a continue decrease along the exposure period. As it is shown in Fig. 1, the decrease of $P^{*}{ }_{M}$ over the first and second year is more significant than the decrease of $P^{*}{ }_{M}$ over the last three years of the analysis period. The effective peak power value is decreased by $22.15 \%$ during the

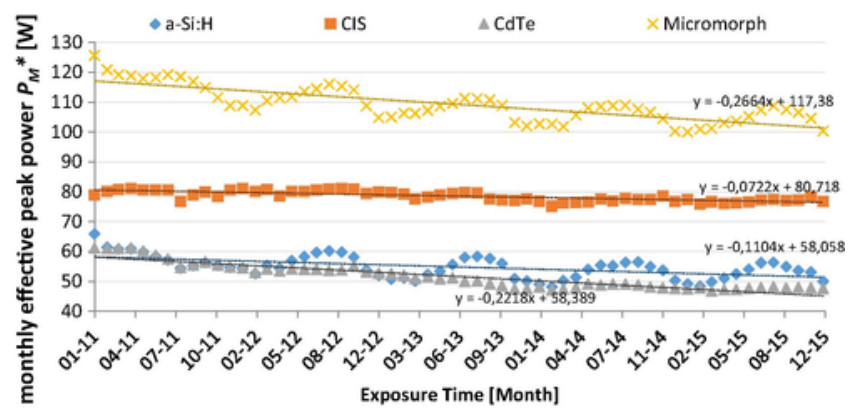

Fig. 1. Evolution of $P^{*}{ }_{M}$ (for $\mathrm{G}>700 \mathrm{~W} / \mathrm{m}^{2}$ ) of the four PV modules along the monitoring campaign. 
five years of the monitoring campaign. The seasonal variation observed in the trend of $P^{*}{ }_{M}$ of the CdTe PV module is smaller than the observed in previous works published in the literature (De la Parra et al., 2013).

Finally, form Fig. 1, it can be observed that $P^{*}{ }_{M}$ corresponding to the CIS PV module exhibits a stable evolution during the exposure period compared to the others technologies. Several works presented in literature confirm the stability of the CIS PV modules when exposed outdoor (Deibel et al., 2002; Ullal et al., 1997; Del Cueto et al., 2008). Moreover, a slight seasonal variation can be observed in the trend of $P^{*}{ }_{M}$, where, the output power increases during the winter months and decreases over the summer months. This can be explained with the relatively high power temperature coefficient of the CIS PV module given in Table 1. The obtained values of $D R$ calculated from the trend line of each PV module are given in Table 3.

\subsubsection{The a-Si:H PV module}

The DR of the a-Si:H PV module presented in Table 2 is in the range of previous results presented in the literature (Jordan and Kurtz, 2013; Kichou et al., 2016a; Phinikarides et al., 2014). The value of $D R$ in a work presented by Kichou et al. is around $-2.30 \% /$ year (Kichou et al., 2016a), while Jordan and Kurtz report DR of a-Si:H PV modules up to $-4.5 \%$ year (Jordan and Kurtz, 2013).

In most cases mean values obtained for the $D R$ are in the range of $-1 \% /$ year to $-2 \% /$ year. These values are similar to $D R$ of $-1.9 \% /$ year reported for mono-crystalline PV modules in Indian climatic conditions (Rajput et al., 2016). Moreover, Phinikarides et al. refer to $D R$ below $-2.4 \% /$ year for a-Si:H PV modules (Phinikarides et al., 2014). The highest degradation rates have been reported in Korea and the Mediterranean region.

The result obtained by applying the filtering process of restricted interval of solar irradiance and cell temperature values is shown in Fig. 2. After one month of exposure under outdoor conditions, a strong initial degradation can be observed, where, the DC output power of the PV module is decreased by around $8.61 \%$. From the second month till April 2012, the DC output power of the a-Si:H PV module is reduced by $18.26 \%$. During the summer months of 2012 , a regeneration of $5 \%$ can be distinguished in the performance of the PV module, and after that, the output power is decreased by the same percentage in winter months.

The stabilization of the DC output power of the a-Si:H PV module occurs after a period of 24 months of operation under the climate of Madrid. In previous works, stabilization periods of 16 months were reported for a-Si:H PV modules under a Continental-Mediterranean climate (Kichou et al., 2016a) and Equatorial climate (Hussin et al., 2015).

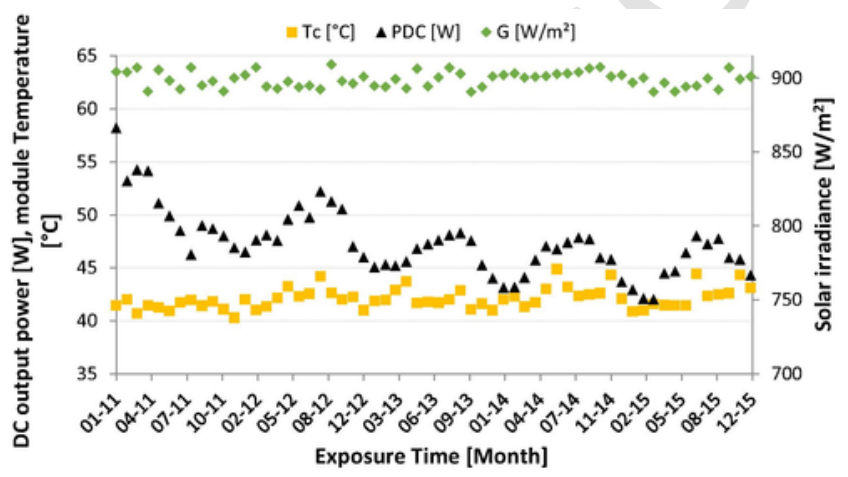

Fig. 2. Monthly values of the DC output power of the a-Si:H PV module obtained by $G$ and $T c$ data in the range of: $890 \mathrm{~W} / \mathrm{m}^{2}<\mathrm{G}<910 \mathrm{~W} / \mathrm{m}^{2}$ and $40{ }^{\circ} \mathrm{C}<\mathrm{Tc}<45^{\circ} \mathrm{C}$.
The stabilized level of DC output power of the PV module is around $45 \mathrm{~W}$ taking into account the range of $G$ and $T c$ considered in the data filtering process. In the following months, the DC power demonstrates a sinusoidal trend attributable to the annealing effects. The effect of seasonal oscillation remains after the stabilization period for about $5.5 \%$ variation from the stabilized level of DC power. A similar result, $4 \%$, was reported in Rome climatic conditions (Pierro et al., 2015).

\subsubsection{Micromorph PV module}

The $D R$ of the micromorph PV module is found to be $-2.72 \% /$ year. This value of $D R$ is in the range of results obtained in a previous work where $D R$ values of $-2.20 \%$ year were reported (Kichou et al., 2016b).

The analysis of the stabilization period of the micromorph PV module is carried out by following the same steps presented above. In the second monitoring data filtering process, the selected ranges of $G$ and $T c$ are the same as those selected for the a-Si:H PV module, $890 \mathrm{~W} / \mathrm{m}^{2}<G<910 \mathrm{~W} / \mathrm{m}^{2}$ and $40{ }^{\circ} \mathrm{C}<T c<45^{\circ} \mathrm{C}$.

The evolution of the filtered DC output power of the micromorph PV module over the time is shown in Fig. 3. Similarly to the case of a-Si:H, a strong initial decrease of the DC output power is observed after the first months of exposure followed by a smooth variation according to the seasonal climate changes. After four months of deployment under outdoor conditions, the DC output power generated by the Micromorph PV module was degraded by about $8.83 \%$. This degradation is mainly associated to the LID that affects the top amorphous layer of the solar cell. In the following months, the DC output power shows a sinusoidal trend attributable to the annealing effects.

Previous works based on the study of degradation of micromorph PV modules commercialized by Kaneka indicate that the stabilization period is from two weeks till a few months (Hussin et al., 2015), and around four months under a Continental-Mediterranean climate (Kichou et al., 2016b).

The $P_{D C}$ values of January 2011 and January 2012 are equal to $115.06 \mathrm{~W}$ and $93.38 \mathrm{~W}$ respectively; this means that the output power of the PV module was degraded by $18.84 \%$. On the other hand, the $P_{D C}$ values of August 2011 and August 2012 are equal to $103.93 \mathrm{~W}$ and $100.81 \mathrm{~W}$ respectively; this leads to degradation of $3 \%$. Therefore, by comparing the difference between the values of $D R$ obtained from winter and summer months, the stabilization period is identified to be equal to four months after a decrease of $17.4 \%$ in the $P_{D C}$ value.

After three years of exposure under outdoor conditions, a reduction of the output power of around 5.6\% from the stabilized value was observed leading to a total degradation of $23 \%$.

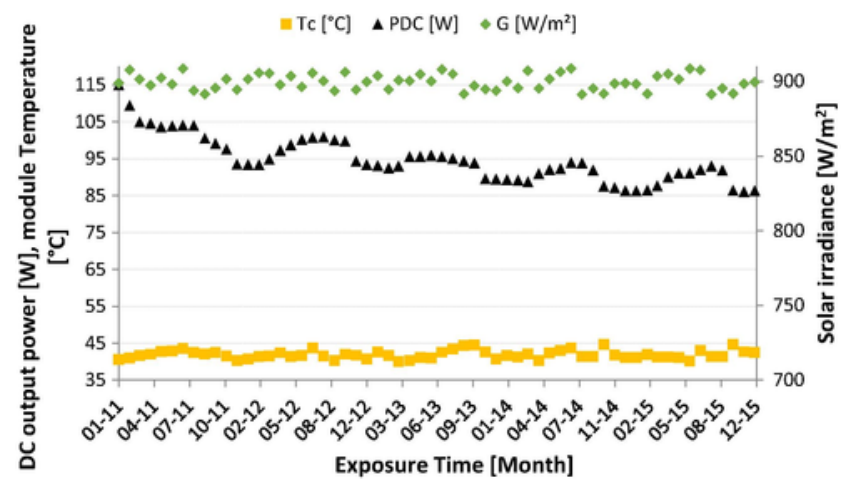

Fig. 3. Monthly values of the DC output power of the micromorph PV module obtained by $G$ and $T c$ data in the range of: $890 \mathrm{~W} / \mathrm{m}^{2}<G<910 \mathrm{~W} / \mathrm{m}^{2}$ and $40{ }^{\circ} \mathrm{C}<T c<45^{\circ} \mathrm{C}$. 
The effect of seasonal oscillation remains after the stabilization period with variations about $3.7 \%$ from the stabilized level of DC output power. Compared with the a-Si:H PV module, the LID phenomenon and the seasonal variation are less significant due to the effect of the $\mu \mathrm{c}-\mathrm{Si}: \mathrm{H}$ layer.

\subsubsection{CdTe PV module}

From Table 2 it can be seen that the CdTe PV module presents the highest $D R$ compared to the other technologies. Previous works available in the literature present $D R$ of $-1.5 \% /$ year and $-3.5 \% /$ year using the same linear regression method adopted in this study (Jordan and Kurtz, 2013; Phinikarides et al., 2014).

The analysis of the stabilization period of the CdTe PV module is carried out by following the same method presented in the previous section, with the same ranges of $G$ and $T c$ selected previously in the second monitoring data filtering process.

Fig. 4 displays the results obtained after the filtering process. As it can be seen, the DC output power generated by the CdTe PV module presents a strong steady decrease during the first two years of exposure under outdoor conditions. The output power degraded of around $21.9 \%$ in two years and a half. A significant decrease in the performance of CdTe PV modules is also reported in the literature by Carlsson and Brinkman (Carlsson and Brinkman, 2006), where the CdTe PV modules degraded of around $13 \%$ in a period of 18 months.

After a period of 30 months, the degradation of the CdTe PV module is very slight and the stabilization can be observed in the trend of the output power generated by the PV module.

The stabilization of the DC output power of the CdTe PV module can be estimated to occur after a period of 32 months of operation under the climate of Madrid. With the selected ranges of $G$ and $T c$ chosen in the data filtering process, the DC output power of the CdTe PV module stabilizes around 41.6 W. However, a slight seasonal variation can be still be observed, but very small: $\pm 2 \%$ of the stabilized DC output power.

\subsubsection{CIS PV module}

The DR obtained for the CIS PV module is $-1.04 \% / y e a r$, as it is shown in Table 2. This value of $D R$ is in the range of other works previously developed for different locations: $-0.5 \% /$ year (Jordan and Kurtz, 2013) and $-2.72 \%$ /year (Phinikarides et al., 2014).

The analysis of the stabilization period of the CIS PV module is carried out by following the same steps presented in previous sections. In the second monitoring data filtering process, the selected ranges of $G$ and $T c$ are: $890 \mathrm{~W} / \mathrm{m}^{2}<G<910 \mathrm{~W} / \mathrm{m}^{2}$ and $50{ }^{\circ} \mathrm{C}<T c<55^{\circ} \mathrm{C}$.

The result obtained is depicted in Fig. 5. The DC output power generated by the CIS PV module presents a stable trend during the

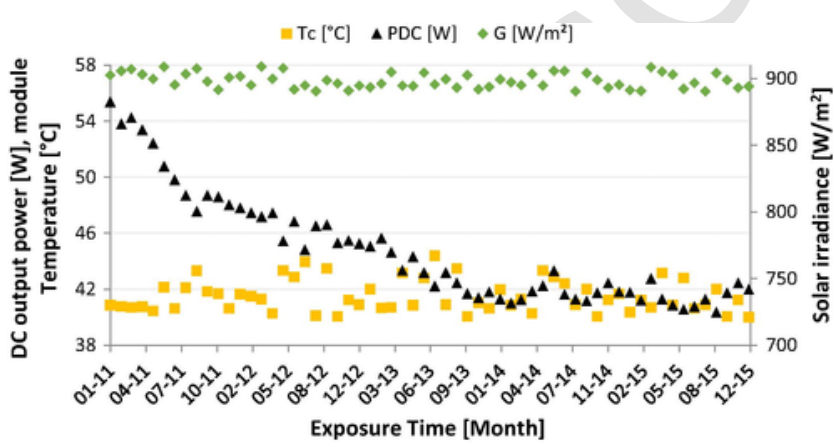

Fig. 4. Monthly values of the DC output power of the CdTe PV module obtained by $\mathrm{G}$ and Tc data in the range of: $890 \mathrm{~W} / \mathrm{m}^{2}<G<910 \mathrm{~W} / \mathrm{m}^{2}$ and $40{ }^{\circ} \mathrm{C}<T c<45{ }^{\circ} \mathrm{C}$.

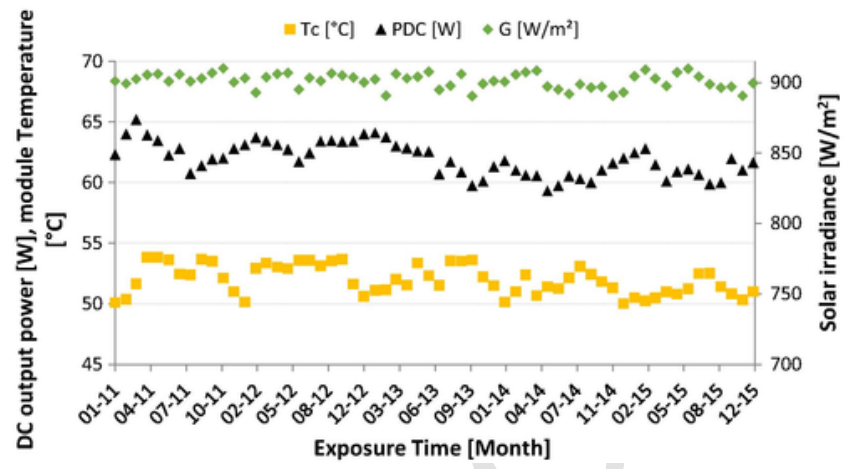

Fig. 5. DC output power of the CIS PV module obtained by $G$ and $T c$ data in the range of: $890 \mathrm{~W} / \mathrm{m}^{2}<G<910 \mathrm{~W} / \mathrm{m}^{2}$ and $50{ }^{\circ} \mathrm{C}<T c<55^{\circ} \mathrm{C}$.

monitoring campaign. No significant degradation can be observed compared to the other technologies presented above. A slight degradation can be noticed after a period of 3 years, where the DC output power value is decreased of $2.66 \%$. Moreover, a slight seasonal variation can be observed in the trend of the DC output power. The output power decreases with the increase of temperature and vice versa, and this can be explained by the relative high value of the temperature coefficient of power of the CIS PV module.

\subsection{Power-irradiance technique}

The Power-Irradiance method was used as a second technique to estimate the stabilization period of the four TFPV modules used in this work.

From the plots of the monthly $P_{D C}$ as a function of irradiance the trend line defined by Eq. (5) is extracted with a LCA. The stabilization period can be estimated by plotting the gradient values obtained from Eq. (5).

Tables 4 and 5 summarise several gradient values and empirical equations obtained by the LCA for each PV module. One value each four month is given in the tables.

\subsection{1. a-Si:H PV module}

The evolution of the gradient values along the monitoring campaign obtained for the a-Si:H PV module is shown in Fig. 6. The gradient values represent clearly the instability of the PV module during the first months of deployment under outdoor conditions. A strong initial decrease can also be observed. The decrease of the gradient values continues during the next months till reaching a sinusoidal trend caused by the seasonal variation.

After a period of 24 months the stabilization of the a-Si:H PV module occurs. This stabilization period matches the stabilization period obtained in Section 4.2.1 by the first method.

\subsubsection{Micromorph PV module}

Fig. 7 depicts the evolution of the gradient values obtained for the micromorph PV module along the exposure period of five years. After the strong initial decrease observed during the first months, the gradient values keep decreasing following the seasonal variation. In this case the rise of the gradient values is observed to occur during the winter months due to the domination of the temperature effects in the $\mu \mathrm{c}-\mathrm{Si}$ :H layer.

Concerning the stabilization period, the result obtained is four months, identical to the value obtained in Section 4.1.2. 
Table 4

Gradient values and empirical equations obtained for the a-Si:H and micromorph PV modules.

\begin{tabular}{|c|c|c|c|c|c|c|}
\hline \multirow[t]{2}{*}{ Month } & \multicolumn{3}{|l|}{$\mathrm{a}-\mathrm{Si}: \mathrm{H}$} & \multicolumn{3}{|c|}{ Micromorph } \\
\hline & Gradient & $\mathrm{R}^{2}$ & Empirical equation & Gradient & $\mathrm{R}^{2}$ & Empirical equation \\
\hline January-11 & 0.0680 & 0.950 & $P_{D C}=0.0680 G+3.701$ & 0.1343 & 0.969 & $P_{D C}=0.1343 G-3.250$ \\
\hline May-11 & 0.0517 & 0.947 & $P_{D C}=0.0517 G+4.938$ & 0.1071 & 0.967 & $P_{D C}=0.1071 G+3.451$ \\
\hline September-11 & 0.0573 & 0.930 & $P_{D C}=0.0573 G+6.242$ & 0.1031 & 0.962 & $P_{D C}=0.1031 G+5.155$ \\
\hline January-12 & 0.0504 & 0.934 & $P_{D C}=0.0504 G+0.901$ & 0.1117 & 0.931 & $P_{D C}=0.1117 G-4.411$ \\
\hline May-12 & 0.0511 & 0.964 & $P_{D C}=0.0511 G+1.860$ & 0.1045 & 0.967 & $P_{D C}=0.1045 G+0.474$ \\
\hline September-12 & 0.0506 & 0.963 & $P_{D C}=0.0506 G+2.469$ & 0.1022 & 0.956 & $P_{D C}=0.1022 G+4.779$ \\
\hline January-13 & 0.0470 & 0.934 & $P_{D C}=0.0470 G-1.253$ & 0.1152 & 0.966 & $P_{D C}=0.1152 G-2.225$ \\
\hline May-13 & 0.0491 & 0.970 & $P_{D C}=0.0491 G+1.794$ & 0.1037 & 0.964 & $P_{D C}=0.1037 G-0.284$ \\
\hline September-13 & 0.0510 & 0.958 & $P_{D C}=0.0510 G+1.539$ & 0.0981 & 0.975 & $P_{D C}=0.0981 G+4.317$ \\
\hline January-14 & 0.0474 & 0.883 & $P_{D C}=0.0474 G+1.462$ & 0.1064 & 0.928 & $P_{D C}=0.1064 G-3.666$ \\
\hline May-14 & 0.0503 & 0.912 & $P_{D C}=0.0503 G+1.356$ & 0.0946 & 0.962 & $P_{D C}=0.0946 G-3.770$ \\
\hline September-14 & 0.0501 & 0.971 & $P_{D C}=0.0501 G+2.213$ & 0.0975 & 0.979 & $P_{D C}=0.0975 G-0.039$ \\
\hline January-15 & 0.0476 & 0.923 & $P_{D C}=0.0476 G-1.006$ & 0.1058 & 0.972 & $P_{D C}=0.1058 G+0.556$ \\
\hline May-15 & 0.0473 & 0.965 & $P_{D C}=0.0473 G+2.253$ & 0.0931 & 0.955 & $P_{D C}=0.0931 G+4.055$ \\
\hline September- 15 & 0.0503 & 0.949 & $P_{D C}=0.0503 G+3.419$ & 0.0962 & 0.957 & $P_{D C}=0.0962 G+4.226$ \\
\hline
\end{tabular}

Table 5

Gradient values and empirical equations obtained for the CdTe and CIS PV modules.

\begin{tabular}{|c|c|c|c|c|c|c|}
\hline \multirow[t]{2}{*}{ Month } & \multicolumn{3}{|l|}{$\mathrm{CdTe}$} & \multicolumn{3}{|l|}{ CIS } \\
\hline & Gradient & $\mathrm{R}^{2}$ & Empiricalequation & Gradient & $\mathrm{R}^{2}$ & Empiricalequation \\
\hline January-11 & 0.0578 & 0.946 & $P_{D C}=0.0578 G+3.297$ & 0.0692 & 0.930 & $P_{D C}=0.0692 G+5.619$ \\
\hline May-11 & 0.0517 & 0.947 & $P_{D C}=0.0517 G+4.938$ & 0.0637 & 0.911 & $P_{D C}=0.0637 G+5.102$ \\
\hline September-11 & 0.0453 & 0.931 & $P_{D C}=0.0453 G+6.241$ & 0.0592 & 0.914 & $P_{D C}=0.0592 G+8.088$ \\
\hline January-12 & 0.0489 & 0.887 & $P_{D C}=0.0489 G+3.342$ & 0.0708 & 0.890 & $P_{D C}=0.0708 G+3.887$ \\
\hline May-12 & 0.0485 & 0.937 & $P_{D C}=0.0485 G+2.500$ & 0.0721 & 0.920 & $P_{D C}=0.0721 G-2.264$ \\
\hline September-12 & 0.0439 & 0.922 & $P_{D C}=0.0439 G+5.804$ & 0.0612 & 0.914 & $P_{D C}=0.0612 G+7.219$ \\
\hline January-13 & 0.0449 & 0.908 & $P_{D C}=0.0449 G+3.132$ & 0.0801 & 0.866 & $P_{D C}=0.0801 G-2.858$ \\
\hline May-13 & 0.0452 & 0.961 & $P_{D C}=0.0452 G+3.867$ & 0.0667 & 0.943 & $P_{D C}=0.0667 G+3.963$ \\
\hline September-13 & 0.0432 & 0.911 & $P_{D C}=0.0432 G+5.107$ & 0.0598 & 0.905 & $P_{D C}=0.0598 G+6.058$ \\
\hline January-14 & 0.0434 & 0.822 & $P_{D C}=0.0434 G+2.520$ & 0.0752 & 0.894 & $P_{D C}=0.0752 G-1.023$ \\
\hline May-14 & 0.0435 & 0.926 & $P_{D C}=0.0435 G+0.257$ & 0.0733 & 0.904 & $P_{D C}=0.0733 G-4.826$ \\
\hline September-14 & 0.0423 & 0.903 & $P_{D C}=0.0423 G+3.511$ & 0.0600 & 0.941 & $P_{D C}=0.0600 G+7.170$ \\
\hline January-15 & 0.0434 & 0.838 & $P_{D C}=0.0434 G-0.567$ & 0.0745 & 0.879 & $P_{D C}=0.0745 G-1.922$ \\
\hline May-15 & 0.0407 & 0.937 & $P_{D C}=0.0407 G+5.903$ & 0.0583 & 0.911 & $P_{D C}=0.0583 G+6.979$ \\
\hline September- 15 & 0.0408 & 0.906 & $P_{D C}=0.0408 G+6.143$ & 0.0590 & 0.935 & $P_{D C}=0.0590 G+6.784$ \\
\hline
\end{tabular}

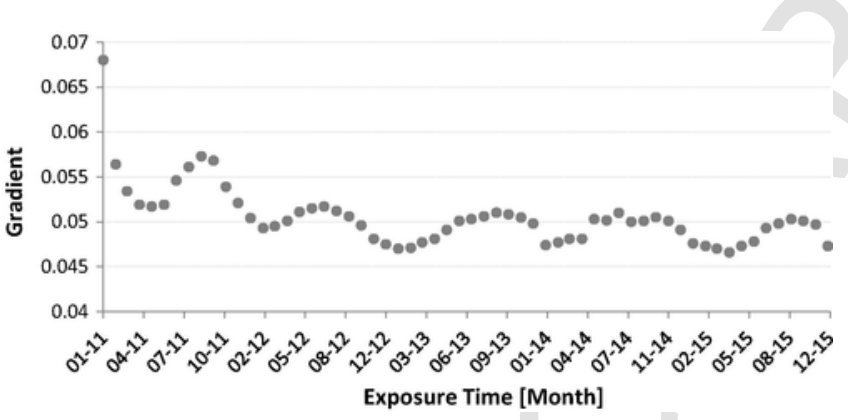

Fig. 6. Evolution of the gradient values obtained for a-Si:H PV module.

\subsubsection{CdTe PV module}

From the evolution of the gradient values for the CdTe PV module plotted in Fig. 8, it can be observed a continue decrease in the trend of the gradient. After a long period of 32 months, the evolution of the gradient values stabilizes around the value 0.0425 , reflecting the stabilization of the output power generated by PV module. The stabilization period obtained by the P-G technique coincide with the stabilization period obtained by the first method presented above.

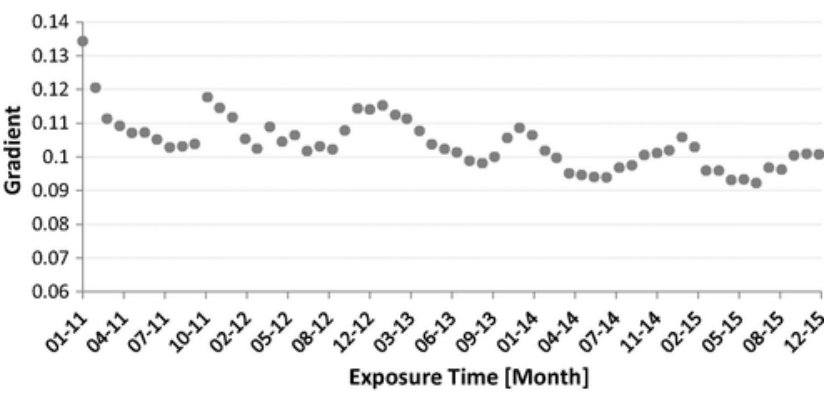

Fig. 7. Evolution of the gradient values obtained for micromorph PV module.

\subsubsection{CIS PV module}

Finally, the evolution of the gradient values obtained for the CIS PV module is shown in Fig. 9. After a period of five years of deployment, no significant degradation can be observed, while a sinusoidal trend is present due to the seasonal variation. The results obtained using both methods confirm the stability of the CIS PV module and it can be observed that the PV module performs better during winter months. However, the DC output power value is decreased of $2.66 \%$ after a period of 3 years, has it was shown in Fig. 5. Moreover, a slight seasonal variation of $\pm 2.1 \%$ can be observed in the trend of the DC output power in Fig. 5. 


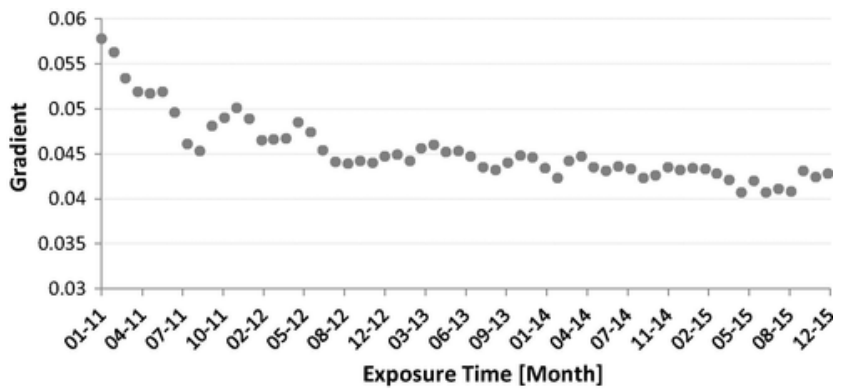

Fig. 8. Evolution of the gradient values obtained for CdTe PV module.

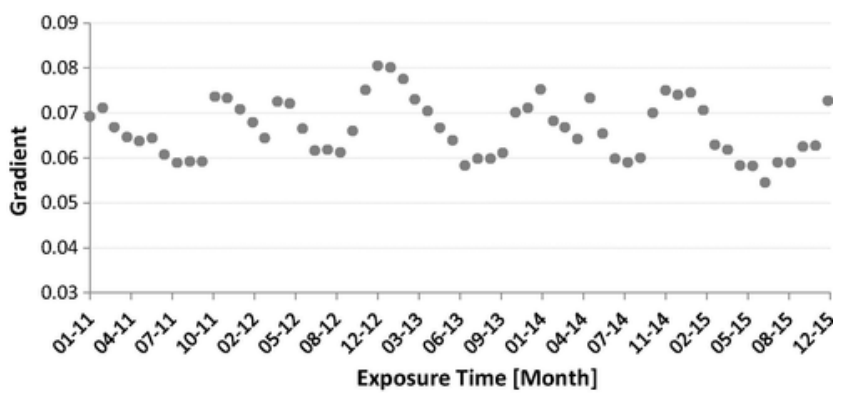

Fig. 9. Evolution of the gradient values obtained for CIS PV module.

\subsection{Fill factor and performance ratio evolution}

The evolution of the monthly fill factor values, FF (\%), calculated for each PV module, is shown in Fig. 10. It can be seen that the evolution of the monthly FF of each PV module is in accordance with the results obtained in the previous sections.

Regarding the a-Si:H and the micromorph PV modules, the initial degradation and the seasonal variation are also present in the evolution of their monthly FF. The stabilized value of the FF for the a-Si:H PV module is around $57 \%$. For the micromorph PV module, the FF firstly stabilizes around $62 \%$ and, after a period of three years, diminishes to $60 \%$. Comparing these two PV modules, the effect of the $\mu \mathrm{c}-\mathrm{Si}$ :Hbottom layer can be clearly seen in the enhanced performance of the micromorph PV module.

The trend of the monthly FF obtained for the CdTe PV module demonstrates a continue degradation in the performance of the PV module. The value of the FF stabilizes around 53\% representing the worst value compared to the other PV module technologies.

Finally, the high values of the monthly FF obtained for the CIS PV module reflect the stability in the performance of this PV module. It can be seen from Fig. 10 that the monthly FF values fluctuate

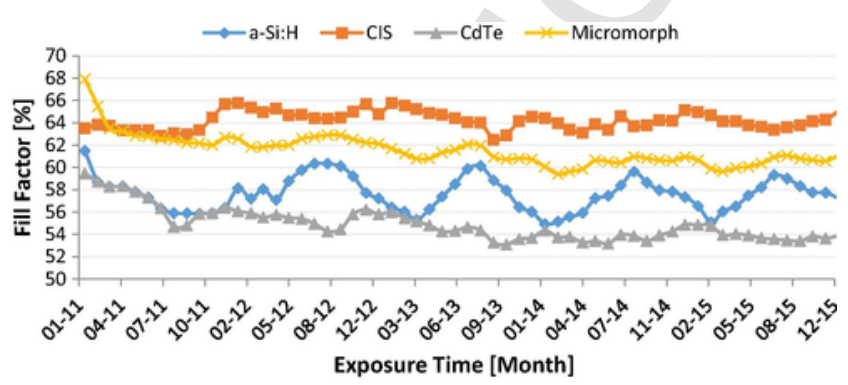

Fig. 10. Evolution of the FF along the exposure period. around $64 \%$ following the seasonal variation previously observed for the CIS PV module.

The monthly values of the performance ratio, $P R$, calculated using Eq. (6) are plotted in Fig. 11. As it can be seen, the same trends of degradation are obtained.

For the a-Si:H PV module the initial degradation is also observed in the trend of the $P R$ shown in Fig. 11. The $P R$ stabilizes around the $85 \%$ following the seasonal variation. These seasonal PR fluctuations are around $10 \%$, similar to results reported in the literature in Rome climatic conditions (Pierro et al., 2015).

From the trend of the $P R$ obtained for the micromorph PV module, it can be seen an initial degradation, followed by a first stabilization around $89 \%$ and a further reduction of $5.61 \%$ after a period of three years. $P R$ of $91 \%$ with an important seasonal variation was reported for micromorph PV modules after one year operation in temperate climates (Aste et al., 2014).

The evolution of the $P R$ calculated for the CIS PV module demonstrates stable fluctuations around the value of $90 \%$ following the seasonal variation.

Finally for the CdTe PV module, it can be seen from Fig. 11 that the continue degradation along a period of 32 months clearly affects the performance of the PV module, with a PR degrading from $85 \%$ to $69 \%$.

\section{Conclusion}

The evaluation of performance degradation under 5 years of outdoor exposure of four TFPV modules corresponding to four different technologies: a-Si:H, a-Si:H/ $\mu \mathrm{c}-\mathrm{Si}: \mathrm{H}, \mathrm{CdTe}$ and CIS, was addressed in this work. The PV modules were deployed in Leganés, a city within the metropolitan area of Madrid (Spain). This is a dry and sunny inland site with a Continental-Mediterranean Climate. The results obtained are referred to one PV module for each of the technologies tested so that these results cannot be considered as general results.

The values of $D R$ were evaluated by linear regression from the evolution of the modules effective peak power. The stabilization periods were assessed by observing the evolution of the output $P_{D C}$ and through the power-irradiance technique.

The values of $D R$ for all the technologies were found to be in the range of previous studies except for the CdTe PV module. This module presents a higher degradation rate than expected, as well as a very high loss of effective peak power over the five years. The CIS PV module is found to be the most stable, presenting the lowest values of $D R$ and power loss.

Regarding the stabilization period, the a:Si:H and micromorph silicon modules present results in good agreement with the literature, even if stabilization periods found in previous studies for a:Si:HTFPV modules are slightly shorter. In both a:Si:H and micromorph technologies, a strong degradation is observed during the first

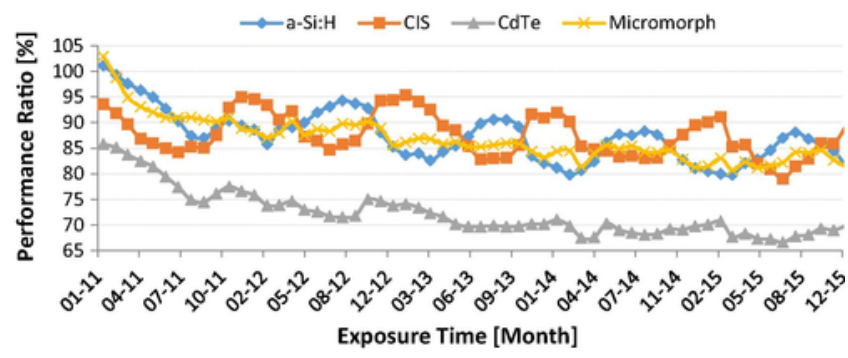

Fig. 11. Evolution of the PR along the exposure period. 
month of outdoor exposure, where the DC output power drops of $8.61 \%$ and $8.42 \%$ respectively. In both technologies the instability is mainly due to the a-Si:H layer. In the micromorph TFPV module, however, the layer of a-Si:H is significantly thinner than in the a-Si:Hmodule. This fact, together with the presence of the more stable $\mu \mathrm{Si}: \mathrm{H}$ bottom layer, allows the micromorph module to have a significantly shorter stabilization period than that of the a-Si:Hmodule. The CdTe PV module degrades steadily for a very long period, during which the output $P_{D C}$ degrades over $22 \%$ before showing stabilization. This result is in disagreement with previous works reported in the literature, which state CdTe to be a stable technology. On the other hand, the CIS PV module shows a very stable trend, with only $2.66 \%$ of $P_{D C}$ loss over the 5 years of experimental campaign lasted and a $D R$ of $-1.04 \% /$ year.

As a summary, the CIS PV module was found to be the most stable of the four PV modules, under long term outdoor exposure in a dry and sunny inland site. The amorphous and micromorph modules also perform quite well, showing degradation rates and stabilization periods similar to the expectations. However their performances appear to be lower than what stated in the manufacturer datasheets, especially regarding the values of stabilized effective peak power. The CdTe module shows poor performances, with high degradation rate and power losses, and the power output is always well below the datasheet value.

Finally, the evolution of the monthly values obtained for the $F F$ and $P R$ is in line with degradation trends observed for all TFPV modules analysed.

\section{Acknowledgements}

The authors sincerely thank the financial support provided by the Spanish Science and Innovation Ministry and the ERDF within the frame of the project 'Estimacion de la energia generada por módulos fotovoltaicos de capa delgada: influencia del espectro' under expedient code ENE2008-05098/ALT. This work was also supported by the Centre for Advanced Studies in Energy and Environment (University of Jaén) within the frame of the project 'Caracterización y modelado de las irradiancias espectrales global sobre plano inclinado y directa normal mediante técnicas estadísticas y de inteligencia artificial'.

Appendix A. Experimental assessment on the spectral match of spectra recorded in Leganés at values of irradiance above $700 \mathrm{~W} /$ $\mathbf{m}^{2}$

\section{A.1. Introduction}

This annex is intended to show how spectral measurements corresponding to irradiances above $700 \mathrm{~W} / \mathrm{m}^{2}$ recorded in Leganés over the course of the experimental campaign match the AM 1.5G reference spectrum according to similar criteria to those used by the IEC to evaluate the spectral mismatch of a solar simulator (IEC, 2007). The analysed spectral instances were collected from January 2012 to December 2013 totalizing 40,554 samples, including those scanned below $700 \mathrm{~W} / \mathrm{m}^{2}$. This is a number of samples which suffices to assess the spectral matching over the whole data collection period which ranges from January 2011 to December 2015.

\section{A.2. Methodology}

The average photon energy (APE, in $\mathrm{eV}$ ) was originally proposed by Jardine et al. (2002), as the average energy of all photons from a given solar spectrum distribution. Since then it has become a popular and widespread index to assess whether blue light or red light is enhanced in an actual spectrum when compared with the AM1.5G reference spectrum. Thus, APE may be written as follows:

$$
\mathrm{APE}=\frac{\int_{a}^{b} E(\lambda) d \lambda}{q \int_{a}^{b} \phi(\lambda) d \lambda}
$$

where $E(\lambda)\left[\mathrm{W} \cdot \mathrm{m}^{-2} \cdot \mathrm{nm}^{-1}\right]$ is the spectral irradiance, $\Phi(\lambda)$ $\left[\mathrm{m}^{-2} \cdot \mathrm{nm}^{-1} \cdot \mathrm{s}^{-1}\right]$ is the spectral photon flux density, $q$ is a constant that numerically equals the electronic charge $\left[\mathrm{J} \cdot \mathrm{eV}^{-1}\right], a[\mathrm{~nm}]$ and $b[\mathrm{~nm}]$ are the lower and upper wavelength limits, respectively, of the waveband under study. The latter two limits are usually determined by the measurement range of the spectro-radiometer used. Specifically in our case, $a=350 \mathrm{~nm}$ and $b=1050 \mathrm{~nm}$. Thus, APE for the AM1.5G reference spectrum equals $1.88 \mathrm{eV}$ for this measurement range. Therefore, higher values of this index imply spectra shifted to shorter wavelengths ('blue shifted') whilst lower ones imply spectra shifted to longer wavelengths ('red shifted').

The methodology used by IEC (2007) to classify a solar simulator according to its spectral match is summarized in what follows. First, the waveband ranging from 400 to $1000 \mathrm{~nm}$ in a spectrum generated by a solar simulator is divided in six 100-nm bands each contributing a certain percentage to the integrated irradiance. Then, the percentage values to the total irradiance for each spectral band of the spectrum produced by a solar simulator and the AM1.5G reference spectrum are obtained. If the deviation of the percentages of the spectrum produced by a solar simulator from those of the AM 1.5 reference spectrum lie within $\pm 25 \%$, the simulator obtains 'A-Class' regarding spectral match. This spectral matching requirement has been adopted in this work to analyze natural sunlight spectrum matching at values of irradiance above $700 \mathrm{~W} / \mathrm{m}^{2}$ in Leganés, following the methodology of some other previous contributions (Minemoto et al., 2009; Norton et al., 2015).

\section{A.3. Results and conclusion}

Over $97 \%$ of all the spectral instances collected from January 2012 to December 2013 corresponding to $G>700 \mathrm{~W} / \mathrm{m}^{2}$ yield values of APE ranging from 1.84 to $1.90 \mathrm{eV}$. As it can be easily derived from above, spectra scanned with APE lying within $1.85 \pm 0.01 \mathrm{eV}$ and $1.89 \pm 0.01 \mathrm{eV}$ correspond to "reddest" and "bluest" ones, The former are usually recorded in winter when the sun elevation is low, while the latter are measured during clear days in late spring and early summer when the sun elevation is high.

The broadband irradiance was integrated for each data binned in the above two sets of spectral measurements between 350 and $1050 \mathrm{~nm}$ using the trapezoidal rule. Then, the wavelength range was divided into fourteen $50-\mathrm{nm}$ bands so that the percentage contribution $\left(R_{c}\right)$ of each band to the calculated broadband irradiance was obtained. Mean values of $R_{c}\left(\left\langle R_{c}\right\rangle\right)$ in each 50-nm band were calculated for both APE intervals. The standard deviation was also calculated for each of these bands to estimate the dispersion in the values of $R_{c}$ around its mean value within these two APE intervals.

The blue and red line in Fig. A.1 show the average $R_{c}$ values for every $50-\mathrm{nm}$ band for the two APE intervals under consideration while error bars indicate the standard deviation related to each value of $\left\langle R_{c}\right\rangle$. The green line indicates values of $R_{c}$ for the AM1.5G reference spectrum -restricted to the $350-1050 \mathrm{~nm}$ waveband- across all 


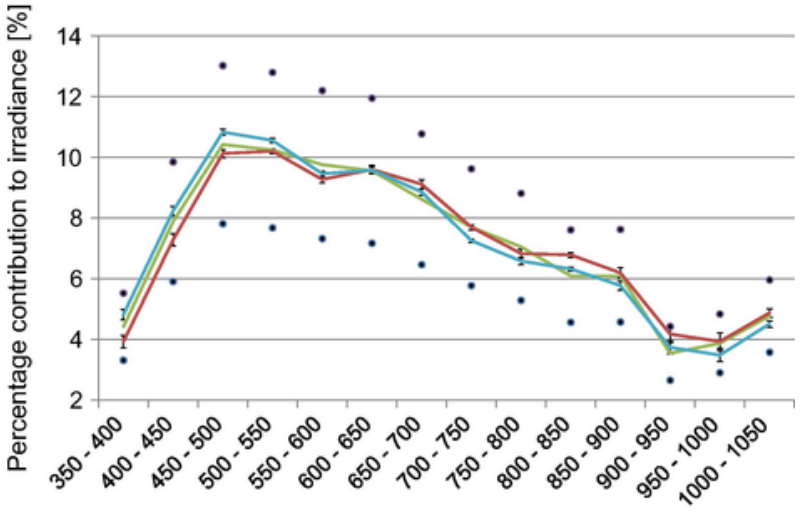

Wavelength band $[\mathrm{nm}]$

Fig. A.1. Average $R_{c}$ values of each $50-\mathrm{nm}$ spectral band for the spectra binned in the APE intervals $1.85 \pm 0.01 \mathrm{eV}$ (red line) and $1.89 \pm 0.01 \mathrm{eV}$ (blue line). The standard deviation related to each value of $\left\langle R_{c}\right\rangle$ is shown by means of error bars. Values of $R_{c}$ of each 50-nm spectral band for the AM1.5G reference spectrum are depicted by a green line while black dots show a deviation of $\pm 25 \%$ from the latter. (For interpretation of the references to color in this figure legend, the reader is referred to the web version of this article.)

50 -nm bands. Black dots above and below the green line indicate the $\pm 25 \%$ deviation allowed for Class-A simulators according to the requirements stated by the IEC. Obviously, spectral measurements binned in the APE interval ranging from 1.88 to $1.90 \mathrm{eV}$ show higher percentage contributions to the integrated irradiance in $50-\mathrm{nm}$ bands with shorter wavelengths. Conversely, percentage contributions in 50-nm bands with longer wavelengths are enhanced for spectral data grouped in the APE interval ranging from 1.84 to $1.86 \mathrm{eV}$. These results are in close agreement with those obtained by Minemoto et al. (2009) and Norton et al. (2015), who carried out a similar analysis -although aimed at a different goal- to that presented here in Kusatsu city (Japan), Golden, Colorado (USA) and Ispra (Italy).

Fig. A.1 clearly shows how values of $\left\langle R_{c}\right\rangle$ corresponding to the spectra with the most enhanced short wavelengths -blue line- and the most enhanced long wavelengths -red line- fit very well the allowable deviation of $\pm 25 \%$-black dots- from percentage contributions across all 50-nm bands to the integrated irradiance of the AM1.5G spectrum. Additionally, such values of $\left\langle R_{c}\right\rangle$ are in very close agreement with those of the AM1.5G reference spectrum for $R_{c}$.

In view of the above results, no spectral correction has been used in Eq. (1). Indeed, spectra corresponding to irradiance levels exceeding $700 \mathrm{~W} / \mathrm{m}^{2}$ in Leganés may be considered similar to the AM1.5G spectrum according to the criteria adopted in this work.

\section{References}

Aste, Niccolò, Del Pero, Claudio, Leonforte, Fabrizio, 2014. PV technologies performance comparison in temperate climates. Sol. Energy 109, 1-10.

Cañete, C., Carretero, J., Sidrach-de-Cardona, M., 2014. Energy performance of different photovoltaic module technologies under outdoor conditions. Energy $65,295-302$.

Carlson, D.E., 2003. Monolithic amorphous silicon alloy solar modules. Sol. Energy Mater. Sol. Cells 78, 627-645.

Carlsson, T., Brinkman, A., 2006. Identification of degradation mechanisms in field-tested CdTe modules. Prog. Photovoltaics: Res. Appl. 14, 213-224.

De la Parra, , Garcia, M.A., Marcos, J., Marroyo, L., 2013 September. A comparative study of degradation and performance of thin film photovoltaic generators versus a multi-crystalline generator. In: Energy Conversion Congress and Exposition (ECCE), 2013 IEEE. IEEE, pp. 4511-4517.

Deibel, C., Dyakonov, V., Parisi, J., Palm, J., Zweigart, S., Karg, F., 2002. Influence of damp heat testing on the electrical characteristics of $\mathrm{Cu}(\mathrm{In}, \mathrm{Ga})(\mathrm{S}, \mathrm{Se}) 2$ solar cells. Thin Solid Films 404, 325-330.
Del Cueto, J.A., Rummel, S., Kroposki, B., Osterwald, C., Anderberg, A., 2008 May. Stability of CIS/CIGS modules at the outdoor test facility over two decades. In: Photovoltaic Specialists Conference, 2008, PVSC'08, 33rd IEEE. IEEE, pp. 1-6.

Green, M.A., Emery, K., Hishikawa, Y., Warta, W., Dunlop, E.D., 2015. Solar cell efficiency tables (version 45). Prog. Photovoltaics: Res. Appl. 23, 1-9.

Hussin, M.Z., Shaari, S., Omar, A.M., Zain, Z.M., 2015. Amorphous silicon thin-film: behaviour of light-induced degradation. Renew. Sustain. Energy Rev. 43, 388-402.

IEC 60904-9 (Ed. 2.0), 2007. Photovoltaic Devices - Part 9: Solar Simulator Performance Requirements. Geneva.

Fraunhofer Institute for Solar Energy Systems, ISE. Photovoltaics Report. Freiburg, 11 March 2016. <https://www.ise.fraunhofer.de/de/downloads/pdf-files/aktuelles/ photovoltaics-report-in-englischer-sprache.pdf $>$.

Ishii, T., Otani, K., Takashima, T., Ikeda, K., 2014. Change in I-V characteristics of thin-film photovoltaic (PV) modules induced by light soaking and thermal annealing effects. Prog. Photovoltaics: Res. Appl. 22, 949-957.

Jardine, C., Betts, T., Gottschalg, R., Infield, D.G., Lane, K., 2002. Influence of spectral effects on the performance of multijunction amorphous silicon cells. In: Proc. of PV in Europe - From PV Technology to Energy Solutions, Rome, Italy.

Jordan, D.C., Kurtz, S.R., 2013. Photovoltaic degradation rates - an analytical review. Prog. Photovoltaics: Res. Appl. 21, 12-29.

Kichou, S., Silvestre, S., Nofuentes, G., Torres-Ramírez, M., Chouder, A., Guasch, D., 2016. Characterization of degradation and evaluation of model parameters of amorphous silicon photovoltaic modules under outdoor long term exposure. Energy 96, 231-241.

Kichou, S., Abaslioglu, E., Silvestre, S., Nofuentes, G., Torres-Ramírez, M., Chouder, A., 2016. Study of degradation and evaluation of model parameters of micromorph silicon photovoltaic modules under outdoor long term exposure in Jaén, Spain. Energy Convers. Manage. 120, 109-119.

Kichou, S., Silvestre, S., Nofuentes, G., Torres-Ramírez, M., Chouder, A., Guasch, D., 2016. Behavioral data of thin-film single junction amorphous silicon (a-Si) photovoltaic modules under outdoor long term exposure. Data Brief 7, 366-371.

Martínez-Moreno, F., Lorenzo, E., Muñoz, J., Moretón, R., 2012. On the testing of large PV arrays. Prog. Photovoltaics: Res. Appl. 20, 100-105.

Mendoza-Pérez, R., Sastre-Hernández, J., Contreras-Puente, G., Vigil-Galán, O., 2009. $\mathrm{CdTe}$ solar cell degradation studies with the use of $\mathrm{CdS}$ as the window material. Sol. Energy Mater. Sol. Cells 93 (1), 79-84.

Mendoza-Pérez, R., Sastre-Hernández, J., Contreras-Puente, G., Vigil-Galán, O., 2009. CdTe solar cell degradation studies with the use of $\mathrm{CdS}$ as the window material. Sol. Energy Mater. Sol. Cells 93, 79-84.

Meyer, E.L., van Dyk, E.E., 2003. Characterization of degradation in thin-film photovoltaic module performance parameters. Renew. Energy 28, 1455-1469.

Minemoto, T., Nakada, Y., Takahashi, H., Takakura, H., 2009. Uniqueness verification of solar spectrum index of average photon energy for evaluating outdoor performance of photovoltaic modules. Sol. Energy 83 (8), 1294-1299.

Muñoz-García, M., Marin, O., Alonso-García, M.C., Chenlo, F., 2012. Characterization of thin film PV modules under standard test conditions: results of indoor and outdoor measurements and the effects of sunlight exposure. Sol. Energy $86,3049-3056$.

Nofuentes, G., Aguilera, J., Santiago, R.L., La, De., Casa, J., Hontoria, L., 2006. A reference-module-based procedure for outdoor estimation of crystalline silicon PV module peak power. Prog. Photovoltaics: Res. Appl. 14, 77-87.

Norton, M., Amillo, A.M. Gracia, Galleano, R., 2015. Comparison of solar spectral irradiance measurements using the average photon energy parameter. Sol. Energy $120,337-344$

Phinikarides, A., Kindyni, N., Makrides, G., Georghiou, G.E., 2014. Review of photovoltaic degradation rate methodologies. Renew. Sustain. Energy Rev. 40, 143-152.

Pierro, M., Bucci, F., Cornaro, C., 2015. Full characterization of PV modules in real operating conditions: theoretical model, measurement method and results. Prog. Photovoltaics: Res. Appl. 23 (4), 443-461.

Pierro, M., Bucci, F., Cornaro, C., 2015. Impact of light soaking and thermal annealing on amorphous silicon thin film performance. Prog. Photovoltaics: Res. Appl. 23 (11), 1581-1596.

Rajput, Pramod, Tiwari, G.N., Sastry, O.S., Bora, Birinchi, Sharma, Vikrant, 2016. Degradation of mono-crystalline photovoltaic modules after 22 years of outdoor exposure in the composite climate of India. Sol. Energy 134, 32-44.

Romeo, N., Bosio, A., Tedeschi, R., Canevari, V., 2000. Back contacts to CSS CdS/ CdTe solar cells and stability of performances. Thin Solid Films 361-362, 327-329.

Rüther, R., Del Cueto, J., Tamizh-Mani, G., Montenegro, A.A., Rummel, S., Anderberg, A., Von Roedern, B., 2008 May. Performance test of amorphous silicon modules in different climates-year four: progress in understanding exposure history stabilization effects. In: Photovoltaic Specialists Conference, 2008, PVSC'08, 33rd IEEE. IEEE, pp. $1-5$.

Shah, A., Torres, P., Tscharner, R., Wyrsch, N., Keppner, H., 1999. Photovoltaic technology: the case for thin-film solar cells. Science 285 (5428), 692-698. 
Sharma, V., Sastry, O.S., Kumar, A., Bora, B., Chandel, S.S., 2014. Degradation analysis of a-Si, (HIT) hetro-junction intrinsic thin layer silicon and m-C-Si solar photovoltaic technologies under outdoor conditions. Energy 72, 536-546.

Staebler, D., Wronski, C., 1977. Reversible conductivity changes in discharge-produced amorphous Si. Appl. Phys. Lett. 31 (4), 292-294.

Tossa, Alain K., Soro, Y.M., Thiaw, L., Azoumah, Y., Lionel, Sicot, Yamegueu, D., Claude, Lishou, Coulibaly, Y., Guillaume, Razongles, 2016. Energy performance of different silicon photovoltaic technologies under hot and harsh climate. Energy 103, 261-270.

Ullal, H.S., Zwelbel, K., Von Roedern, B., 1997 September. Current status of polycrystalline thin-film PV technologies. In: Photovoltaic Specialists Conference, 1997, Conference Record of the Twenty-Sixth IEEE. IEEE, pp. 301-305.

Van Dyk, E.E., Audouard, A., Meyer, E.L., Woolard, C.D., 2007. Investigation of the degradation of a thin-film hydrogenated amorphous silicon photovoltaic module. Sol. Energy Mater. Sol. Cells 91, 167-173.
Virtuani, A., Fanni, L., 2014. Seasonal power fluctuations of amorphous siliconthin-film solar modules: distinguishing between different contributions. Prog. Photovoltaics: Res. Appl. 22, 208-217.

Virtuani, A., Pavanello, D., Friesen, G., 2010. Overview of temperature coefficients of different thin film photovoltaic technologies. In: 25th European Photovoltaic Solar Energy Conference and Exhibition/5th World Conference on Photovoltaic Energy Conversion, Proc.. pp. 6-10.

Yamawaki, T., Mizukami, S., Yamazaki, A., Takahashi, H., 1997. Thermal recovery effect on light-induced degradation of amorphous silicon solar module under the sunlight. Sol. Energy Mater. Sol. Cells 47, 125-134. 